9. H. Phillips and R. R. Spitzer, J. Dairy Sci., 29 (1946) 407.

$10 \mathrm{~W}$. J. Kirsten and B. W. Grunbaum, Anal. Chem., 27 (1955) 1806.

11 W. J. Kirsten, Anal. Chem., 25 (I953) 74.

12 H. Weil-Malherbe and R. H. Green, Biochem. J., 49 (I951) 286.

13 R. A. Horrocks, Nature, I64 (1949) 444.

14 P. E. Lindahl, A. Ingrlman-Sundberg, M. Furuhjelm and A. Nilsson, J. Obstet. Gynaecol. Brit. Empire, 63 (1956) 363 .

15 P. E. Lindahl and S. Ross, (unpublished).

${ }_{16}$ D. W. Bishop, Proc. 3rd Iniern. Congr. Animal Reproduct., Cambridge, 1956.

17 R. Moricard and J. Bossu, Assoc. Gynaecol. Obstet., i (1949) 36.

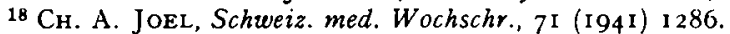

19 L. Rödel AND H. KARG, Fortplantz., Zuchthyg. u. Haustierbesam., 3 (1955) 25.

20 A. Girowd, Ergeb. Vitamin- u. Hormonforsch., I (1938) 68.

Received February 6th, I957

\title{
A NEW HOMOGENIZER FOR THE ISOLATION OF NUCLEI IN CONCENTRATED GLYCERINE
}

\author{
C. POORT \\ Department of Histology and Microscopic Analomy, State University, \\ Utrecht (The Netherlands)
}

Our research into the protein content of the nuclei of beef pancreas, for which a large quantity of nuclei is needed, prompted us to design a homogenizer, capable of liberating the nuclei from several whole glands in a short time.

To reduce as much as possible the loss of protein from the nuclei during the isolation, we chose the medium described by SCHNEIDER ${ }^{1}$, i.e. $70 \%$ glycerine, with the addition of substances which preserve the morphology of the isolated nuclei.

The homogenizer we needed had to fulfill three requirements. Firstly, it should allow continuous operation, since the working up of many small portions is very timeconsuming. This consideration rules out the use of the classical Potter-Elvehjem homogenizer ${ }^{2}$ and related designs (Dounce et al..$^{3}$ and others). Secondly, the degree of homogenization should not depend on manual skill, since this tends to make the results poorly reproducible. Again, the Potter-Elvehjem and similar types do not meet this requirement. In the third place, the homogenizer must be suitable for the viscous $70 \%$ glycerine medium.

The only homogenizers, which to a certain extent meet these requirements, are the Waring blendor and the apparatus proposed by LANG AND SIEBERT ${ }^{4}$. Even though the Waring blendor does not allow a continuous procedure, the quantities it can accomodate are sufficiently large. This apparatus, however, destroys nuclei as well as the other elements and thus causes a large loss of nuclei.

The instrument of LANG AND SIEBERT consists of a cone, rotating within a mantle of the same shape. The suspension to be homogenized is forced by gravity through a narrow slit between the two conical surfaces. This homogenizer, though made for 
continuous operation, is not suitable for our purposes, as it scems to be designed for l'ss viscous tissue suspensions than ours. Besides, its construction calls for very accurate engineering facilities.

The homogenizer, designed by us, while offering the same advantages as that proposed by LANG IND SIEBERT, is easier to make and, moreover, permits the use of viscous media. Essentially, the apparatus consists of a disk A, which rotates over a second disk B (Fig. I). The undersurface of $A$ is plane and accurately parallel to the

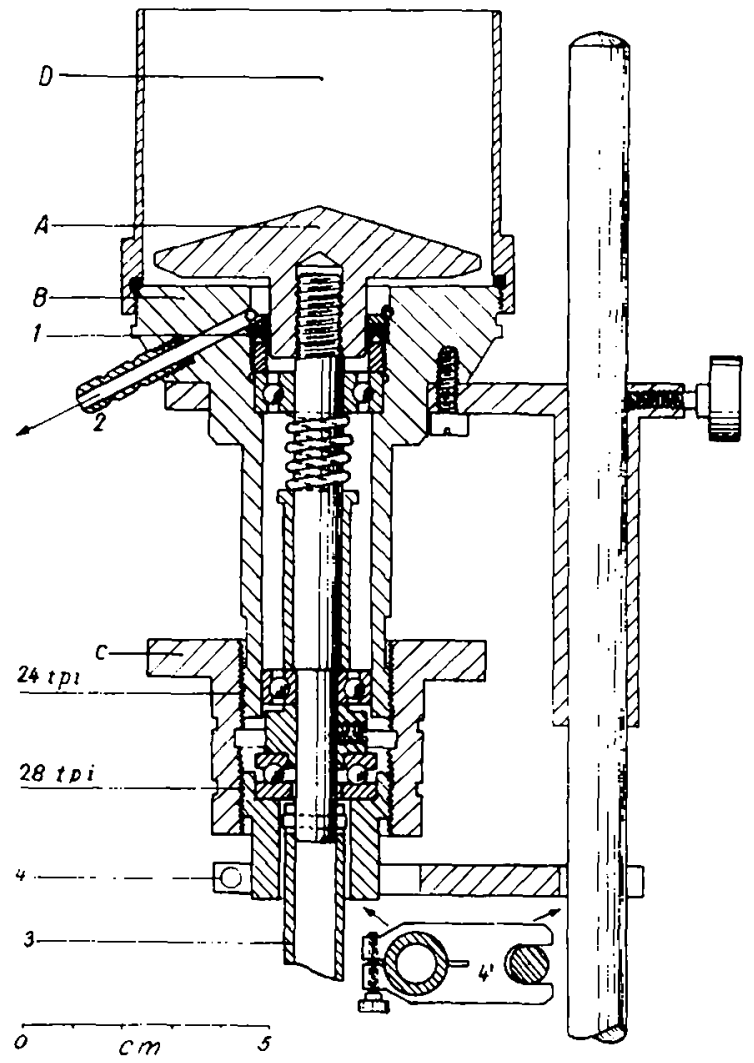

Fig. I. Tissue homogenizer. 1. Packing ring kept in its place by a washer and a circlip. 2. Connection to vacuum pump. 3 . Driving shaft. $4^{\prime}$. Top view of 4 on a reduced scale.

upper surface of B. (Both these surfaces can be easily machined and may be ground against each other to achieve exact parallelism.) The width of the slit between $A$ and $B$ is adjustable by means of the differential screw $C$, one turn of which equals o. $5 \mathrm{~mm}$ change in the slitwidth.

The tissue suspension is introduced at D, from which it is sucked by racuum through the space between $A$ and $B$. The degree of destruction of the tissue depends on:

a) the distance between $A$ and $B$

b) the rotary speed of $A$

c) the pressure difference.

The optimal conditions depend on the tissue used, and should be worked out with the guidance of the microscope. 
We have chiefly worked with beef pancreas, for which the following procedure has proved satisfactory (all operations are carried out at $0-2^{\circ} \mathrm{C}$ ):

The glands are freed as much as possible from fat and the large vessels. Then they are forced through a household vegetable mill by which most of the connective tissue is removed. The brei $(700 \mathrm{~g})$ is mixed in a I:I weight/volume ratio with the glycerinephosphate (0.002 $M \mathrm{~K}_{2} \mathrm{HPO}_{4}$ and $0.002 M \mathrm{KH}_{2} \mathrm{PO}_{4}$, as indicated by SCHNEIDER).

The suspension, which contains, besides broken cells, whole cells and cell-clumps, macroscopically visible pancreas fragments which passed the vegetable mill, is subjected to three successive runs through the homogenizer (speed r50o r.p.m., sufficient vacuum to allow the passage of $50 \mathrm{ml}$ per minute). In order gradually to break down the larger pancreas fragments we begin with a relatively large slitwidth. The settings of the distance between the disks are respectively: first run $0.75 \mathrm{~mm}$, second run $0.45 \mathrm{~mm}$, third run o.15 mm. After this, the suspension contains for the greater part free nuclei but there are still whole cells and even cell clumps present. In order to reduce the time needed for the final run, which is to be made at a much slower rate, the suspension-after layering on the pure medium -is centrifuged for $45 \mathrm{~min}$ at $3000 \mathrm{~g}$ (measured at the bottom of the tubes).

The sediment is resuspended in $100 \mathrm{ml}$ of medium. The resulting suspension is then passed for the last time through the homogenizer (I500 r.p.m., $3 \mathrm{ml}$ per minute, slitwidth $0.075 \mathrm{~mm}$ ), after which it is centrifuged for $60 \mathrm{~min}$ at $3000 \mathrm{~g}$. Usually, the sediment is now found to consist almost exclusively of nuclei. If not, it is once more, resuspended, subjected to a run through the homogenizer at a slitwidth of $0.060 \mathrm{~mm}$, and centrifuged as before.

On microscopical examination, nuclei obtained by this procedure are found to be of a good morphological appearance and without adhering cytoplasmic remnants. About $400 \mathrm{mg}$ of nuclei (dry weight) can thus be isolated from $700 \mathrm{~g}$ beef pancreas.

Many thanks are due to Prof. M. T. JANSE. for his stimulating interest in this work. The skillful assistance of Mr. KERSSEN, the head of our workshop, is gratefully acknowledged.

\section{SUMMARY}

A homogenizer has been designed, which, while being of a simple construction, is capable of liberating nuclei from animal tissues in a continuous and reproducible way.

The apparatus may be used with viscous media.

The isolation procedure of nuclei from beef pancreas in a $70 \%$ glycerine medium is described.

\section{REFERENCES}

1 R. M. Schneider, Exptl. Cell Research, 8 (19.55) 24.

2 V. R. Potter and C. A. Elvehjem, J. Biol. Chem., i 4 (I936) 495.

3 A. I. Dounce, R. F. Witter, K. J. Monty, S. Pate and M. A. Cottone, J. Biophys. Biochem. Cytol., I (I955) 139.

4 K. Lang and G. Siebert, Biochem. Z., 322 (1952) 360. 